\title{
Degradation of the Molecular Weight and Nitrate Ester Content of Cellulose Nitrate on Thermal Aging
}

H. R. Leider

A. J. Pane

June 1981 


\section{DISCLAIMER}

This document was prepared as an account of work sponsored by an agency of the United States Government. Neither the United States Government nor the University of California nor any of their emplovees, makes any warranty, express or implied, or assumes any legal liability or responsibility for the accuracy, completeness, or usefulness of any information, apparatus, product, or process disclosed, or represents that its use would not infringe privately owned rights. Reference herein to any specific commercial products, process, or service by trade name, trademark, manufacturer, or otherwise, does not necessarily constitute or imply its endorsement, recommendation, or favoring by the United States Government or the University of California. The views and opinions of authors expressed herein do not necessarily state or reflect those of the United States Government thereof, and shall not be used for advertising or product endorsement purposes.

Work performed under the auspices of the U.S. Department of Energy by Lawrence L.ivermore National Laboratory under Contract W-7405-Eng-48. 


\section{DISCLAIMER}

This report was prepared as an account of work sponsored by an agency of the United States Government. Neither the United States Government nor any agency Thereof, nor any of their employees, makes any warranty, express or implied, or assumes any legal liability or responsibility for the accuracy, completeness, or usefulness of any information, apparatus, product, or process disclosed, or represents that its use would not infringe privately owned rights. Reference herein to any specific commercial product, process, or service by trade name, trademark, manufacturer, or otherwise does not necessarily constitute or imply its endorsement, recommendation, or favoring by the United States Government or any agency thereof. The views and opinions of authors expressed herein do not necessarily state or reflect those of the United States Government or any agency thereof. 


\section{DISCLAIMER}

Portions of this document may be illegible in electronic image products. Images are produced from the best available original document. 
UCRL-53163

Distribution Category UC-4

\title{
Degradation of the Molecular Weight and Nitrate Ester Content of Cellulose Nitrate on Thermal Aging
}

\author{
H. R. Leider \\ A. J. Pane
}

Manuscript date: June 1981

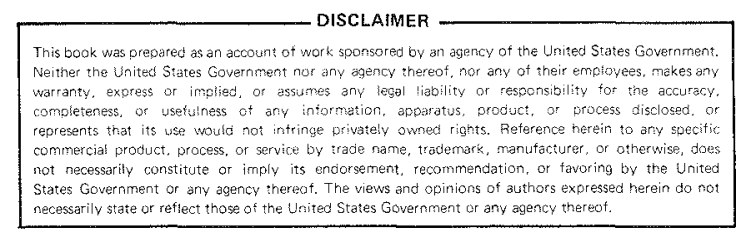

\section{LAWRENCE LIVERMORE LABORATORY} University of California - Livermore, California 94550 



\section{CONTENTS}

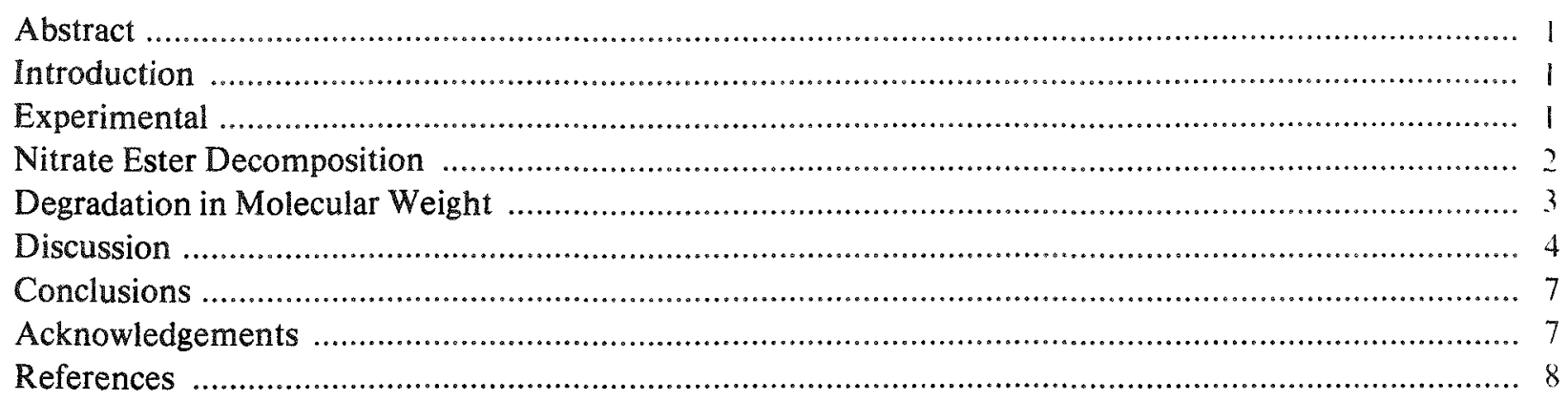




\title{
Degradation of the Molecular Weight and Nitrate Ester Content of Cellulose Nitrate on Thermal Aging
}

\begin{abstract}
Changes in molecular weight and nitrate ester content for cellulose nitrate (NC), either "pure" or as a constituent of PBX-9404, were determined as a function of time and temperature. Changes in the number-averaged molecular weight, $\overline{\mathrm{M}}_{\mathrm{n}}$, are described by the simple theory of random chain scission, and $\bar{M}_{n}$ is found to correlate well with nitrate ester loss. Significant differences are seen between NC aged in the isolated condition and aged as the binder in PBX-9404.
\end{abstract}

\section{INTRODUCTION}

We have recently reported on studies of the thermal stability of the high explosive PBX-9404, 1,2 in which we concluded that decomposition of the cellulose nitrate binder (NC) was responsible for all the observed changes. Our results on gas evolution and weight loss were in general agreement with other reported results obtained under similar conditions ${ }^{3-5}$ and our kinetic description of the decomposition agreed with those determined in the same temperature range for materials containing NC. ${ }^{6-10}$
We have extended our previous work by carrying out additional thermal aging tests on "pure" cellulose nitrate up to $120^{\circ} \mathrm{C}$ and have examined the $\mathrm{NC}$ for changes in molecular weight and nitrate ester content. We show that the degradation in molecular weight of NC, either alone or as a constituent of PBX-9404, can be described using a simple model ${ }^{11}$ and that the changes in molecular weight and in nitrate ester content are intimately connected.

\section{EXPERIMENTAL}

Cellulose nitrate from the same lot used to formulate the PBX-9404 in our earlier work was put into stainless steel containers identical to those previously described. ${ }^{1}$ They were then stored at temperatures ranging from 80 to $120^{\circ} \mathrm{C}$ for times spanning 1 to 30 days, depending on temperature. After aging, the nitrate ester $\left(-\mathrm{ONO}_{2}\right)$ content and molecular weight of the $\mathrm{NC}$ were measured. We did not determine either weight change or gas evolution for these tests.

The $\mathrm{NC}$ samples were analyzed for $\left(-\mathrm{ONO}_{2}\right)$ by an infrared absorbtion method. Samples were dissolved in tetrahydrofuran (THF) and their integrated absorbance between 1600 and $1700 \mathrm{~cm}^{-1}$ was compared to that of a standard calibration curve. The analysis was performed with a concentration of about $10 \mathrm{mg} \mathrm{NC}$ per ml THF using a Digilab Fourier Transform Infrared Spectrometer, model FTS-20C, with a $0.1 \mathrm{~cm} \mathrm{CaF}_{2}$ cell. The error in the determination was better than $\pm 3 \%$ and the precision of duplicates was $\pm 1 \%$ 。

The molecular weight (styrene equivalent) of the NC was measured using gel permeation chromatography on the THF solutions. This technique was described in some detail in a previous report. ${ }^{1}$ Changes in molecular weight of $\pm 5 \%$ could be detected by this method. 


\section{NITRATE ESTER DECOMPOSITION}

The data from the aging test are given in Table 1 for both NC and PBX-9404. The nitrate ester content is given as $\mathrm{X}$, the mean ester number per $\mathrm{NC}$ monomer unit. The starting material is listed as "control." The value of $\mathrm{X}$ for $\mathrm{NC}$ and as-formulated PBX-9404 was the same, but the control condition for the PBX-9404 used in our studies involved a hot-pressing cycle that caused some changes in the NC. The after-pressing NC properties are listed as PBX-9404 controls.

We have already shown ${ }^{2}$ that the loss of $\left(-\mathrm{ONO}_{2}\right)$ from NC in PBX-9404 is well described by the rate expression for a reaction of the type

$$
2\left(-\mathrm{ONO}_{2}\right) \rightarrow \text { Products, }
$$

namely,

$$
k_{2} t=\frac{1}{C(0)}\left[\frac{C(0)-C(t)}{C(t)}\right] .
$$

Here, $\mathrm{k}_{2}$ is the second-order rate constant, $\mathrm{C}(0)$ is the initial concentration, and $C(t)$ is the concentration after time, t. We have fitted our data to Eq. (1) using the same least-squares method that we used before for PBX-9404. ${ }^{2}$ Here we used X as concentration. The resulting values for the secondorder rate constant as a function of temperature for both PBX-9404 and for NC are given in Table 2. Since $k_{2}(T)$ is expected to have the form of an Arrhenius equation, we then least-squares

TABLE 1. Molecular weight and nitrate ester content of NC after thermal aging. (Dashes indicate

\begin{tabular}{|c|c|c|c|c|c|c|c|}
\hline \multirow[b]{2}{*}{$\mathrm{T}\left({ }^{\circ} \mathrm{C}\right)$} & \multirow[b]{2}{*}{$t$ (days) } & \multicolumn{2}{|c|}{ X (mean ester no.) } & \multicolumn{2}{|c|}{$\begin{array}{c}\overline{\mathbf{M}}_{\mathrm{n}} \text { (number-averaged } \\
\text { molecular weight) }\end{array}$} & \multicolumn{2}{|c|}{$\begin{array}{l}\text { MWD (molecular } \\
\text { weight dispersity) }\end{array}$} \\
\hline & & PBX-9404 & $\mathrm{NC}$ & PBX-9404 & $\mathrm{NC}$ & PBX-9404 & $\mathrm{NC}$ \\
\hline \multicolumn{2}{|c|}{ Control } & 2.27 & 2.31 & 5700 & 13100 & 2.79 & 2.75 \\
\hline \multirow[t]{2}{*}{50} & 243 & 2.16 & - & 4200 & - & 2.36 & - \\
\hline & 488 & - & - & 3600 & - & 2.28 & - \\
\hline \multirow[t]{3}{*}{60} & 61 & 2.16 & - & 4100 & - & 2.44 & - \\
\hline & 243 & 2.07 & - & 3400 & - & 2.06 & - \\
\hline & 488 & 1.82 & - & 2700 & - & 1.96 & - \\
\hline \multirow[t]{7}{*}{80} & 20 & - & $2.31^{\mathrm{a}}$ & - & 11900 & - & 2.64 \\
\hline & 28 & 2.02 & - & 3300 & - & 2.09 & - \\
\hline & 30 & - & 2.29 & - & 10900 & - & 2.63 \\
\hline & 59 & 1.89 & - & 2700 & - & 1.89 & - \\
\hline & 84.3 & 1.70 & - & 2600 & - & 1.81 & - \\
\hline & $89^{b}$ & 1.81 & - & 2500 & - & 1.88 & - \\
\hline & $91^{b}$ & 1.63 & - & 1600 & - & 1.50 & - \\
\hline \multirow[t]{3}{*}{90} & 5 & - & $2.31^{a}$ & - & 13000 & - & 2.48 \\
\hline & 10 & - & 2.29 & - & 12400 & - & 2.48 \\
\hline & 20 & - & 2.25 & - & 10700 & - & 2.47 \\
\hline \multirow[t]{4}{*}{100} & 2 & - & 2.30 & - & 12500 & - & 2.74 \\
\hline & 5 & - & 2.28 & - & 10500 & - & 2.83 \\
\hline & 10 & - & 2.20 & - & 9300 & - & 2.87 \\
\hline & 14.2 & 1.82 & - & 2200 & - & 1.73 & - \\
\hline \multirow[t]{3}{*}{120} & 1 & - & 2.18 & - & 10100 & - & 2.71 \\
\hline & 2 & - & 2.00 & - & 5500 & - & 2.76 \\
\hline & 3 & - & 1.89 & - & 4300 & - & 3.05 \\
\hline
\end{tabular}
data not obtained.)

astimated, because our method was not sensitive enough to detect the change in the ester content.

brhese samples had begun accelerated decomposition 1,2 and were not included in the data treatment. 
TABLE 2. Rate constants for decomposition of PBX-9404 and NC. (Dashes indicate data not obtained.)

\begin{tabular}{rccccc}
\hline & \multicolumn{2}{c}{$\begin{array}{c}\mathrm{k}_{2}(\mathrm{~T}) \\
\text { (nitrate ester } \\
\text { loss) }\end{array}$} & \multicolumn{2}{c}{$\begin{array}{c}c \\
\mathrm{k}_{1}(\mathrm{~T}) \\
\text { (molecular weight } \\
\text { degradation) }\end{array}$} \\
\cline { 2 - 5 } $\mathrm{T}\left({ }^{\circ} \mathrm{C}\right)$ & $\mathrm{PBX}-9404$ & $\mathrm{NC}$ & & $\mathrm{PBX}-9404$ & $\mathrm{NC}$ \\
\hline 50 & $9.1 \times 10^{-5^{\mathrm{a}}}$ & - & $2.1 \times 10^{-7}$ & - \\
60 & $2.1 \times 10^{-4}$ & - & $3.7 \times 10^{-7}$ & - \\
80 & $1.7 \times 10^{-3}$ & $1.3 \times 10^{-4^{\mathrm{a}}}$ & $2.5 \times 10^{-6}$ & $4.8 \times 10^{-7}$ \\
90 & - & $5.8 \times 10^{-4}$ & - & $8.9 \times 10^{-7}$ \\
100 & $7.7 \times 10^{-3^{a}}$ & $2.2 \times 10^{-3}$ & $2.0 \times 10^{-5}$ & $3.5 \times 10^{-6}$ \\
120 & - & $3.1 \times 10^{-2}$ & - & $5.5 \times 10^{-5}$ \\
\hline
\end{tabular}

anly a single datum was available, obviating a least-squares nit.

fitted the values of $\ln k_{2}$ vs $1 / T$ and determined that

$$
\begin{array}{r}
\mathrm{k}_{2}(\mathrm{~T})=4.1 \times 10^{10} \mathrm{e}^{-21700 / \mathrm{RT}}\left(\mathrm{r}^{2}>0.99\right), \\
\text { for PBX-9404 }\left(50-100^{\circ} \mathrm{C}\right) \\
\mathrm{k}_{2}(\mathrm{~T})=2.6 \times 10^{19} \mathrm{e}^{-37700 / \mathrm{RT}}\left(\mathrm{r}^{2}>0.99\right), \\
\text { for } \mathrm{NC}\left(80-120^{\circ} \mathrm{C}\right) .
\end{array}
$$

The fits are very good and the difference in activation energies is consistent with a change in decomposition mechanism observed between 80 and $100^{\circ} \mathrm{C} .{ }^{4}$ The values are in general agreement with those reported in the literature ${ }^{1-10}$ in the same temperature regimes.

\section{DEGRADATION IN MOLECULAR WEIGHT}

The degradation in molecular weight of cellulose has been described by the random chainscission model which assumes a first-order mechanism. ${ }^{11}$ This model has recently been applied at this laboratory to a number of other plastic-bonded high explosives. ${ }^{12}$ The molecular weight is given by the equation

$$
\frac{1}{\bar{M}_{n}(t)}=\frac{1}{\bar{M}_{n}(0)}+k_{1} t
$$

where $\bar{M}_{n}(t)$ is the number-averaged molecular weight at time $t, \bar{M}_{n}(0)$ is the initial numberaveraged molecular weight, and $\mathrm{k}_{1}$ is the firstorder rate constant, also assumed to have the Arrhenius form. Figures 1 and 2, for PBX-9404 and $\mathrm{NC}$, respectively, show that our data can be described by Eq. (2). The slope of the least-squares straight line fitted to the data at each temperature determines $\mathrm{k}_{1}(\mathrm{~T})$. The results are given in Table 2 for PBX-9404 and NC. Here, too, a least-squares straight line was fitted to $\operatorname{lnk}$, versus $(1 / T)$; the resulting expressions were

$$
\begin{array}{r}
\mathrm{k}_{1}(\mathrm{~T})=3.7 \times 10^{9} \mathrm{e}^{-24400 / \mathrm{RT}\left(\mathrm{r}^{2}>0.99\right),} \\
\text { for PBX-9404(60-100 } \mathrm{C}), \\
\mathrm{k}_{1}(\mathrm{~T})=3.1 \times 10^{17} \mathrm{e}^{-39100 / \mathrm{RT}\left(\mathrm{r}^{2}>0.99\right)} \\
\text { for } \mathrm{NC}\left(90-120^{\circ} \mathrm{C}\right) .
\end{array}
$$

The fit is excellent and the activation energies are close to those derived from the $\left(-\mathrm{ONO}_{2}\right)$ data. 


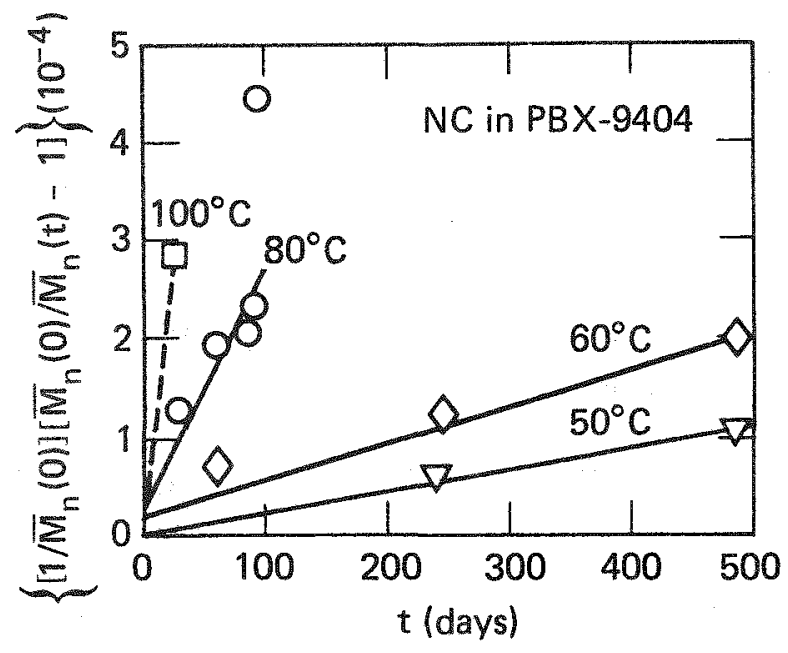

FIG. 1. Degradation of molecular weight of $\mathrm{NC}$ in PBX-9404 as a function of time at several temperatures. Linear relations agree with the random chaim-scission model.

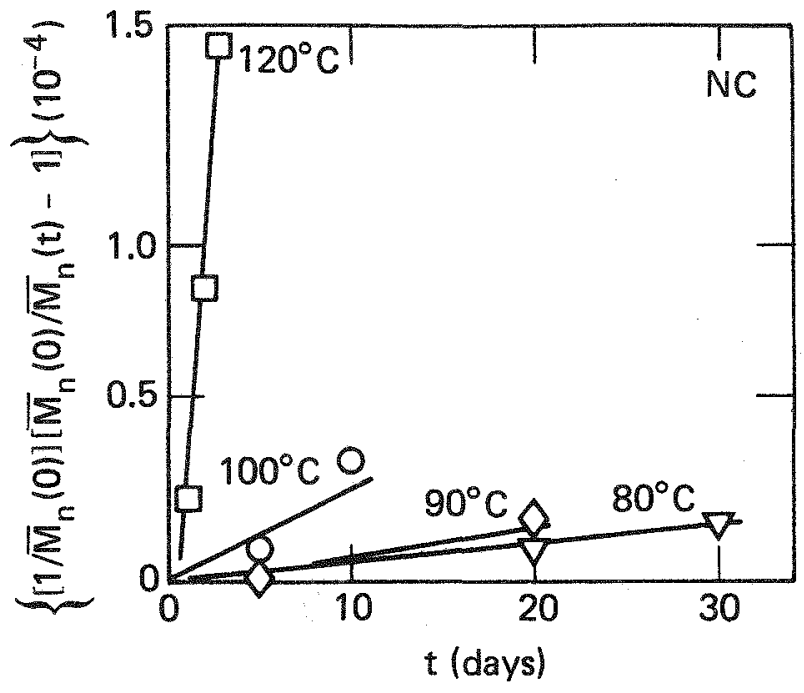

FIG. 2. Degradation of molecular weight of $\mathrm{NC}$ alone as a function of time at several temperatures. Linear relations agree with the random chain-scission model.

\section{DISCUSSION}

Given the basic premise that decomposition of nitrate ester and degradation in molecular weight are directly related, we would expect that both processes would be governed by the same activation energy, even though the processes are described by different mechanisms. This has been demonstrated in our results. An Arrhenius plot of the rate constants is shown in Fig. 3 , in accordance with the least-squares fits discussed in previous sections. As mentioned, the slopes are in good correspondence; however, one difference should be noted. The decomposition rate for $\mathrm{NC}$ in PBX-9404 as compared to that for NC in the temperature region of overlap $\left(80-100^{\circ} \mathrm{C}\right)$ is higher by a factor of 5-10. This difference has been seen by others, ${ }^{4}$ and is attributable to the effects of the other constituents of PBX-9404. In particular, PBX-9404 contains $\sim 0.1 \mathrm{wt} \%$ diphenylamine ${ }^{13}$ as a scavenger for $\mathrm{NO}_{2}$. This material is a Lewis base and is expected to catalyze nitrate ester decomposition. ${ }^{14}$

If we combine Eqs. (1) and (2), we get a correlation between nitrate ester concentration and molecular weight of $\mathrm{NC}$ that can be used as a predictive expression. This way of being able to predict nitrate ester concentration is valuable, because determination of nitrate ester concentration in

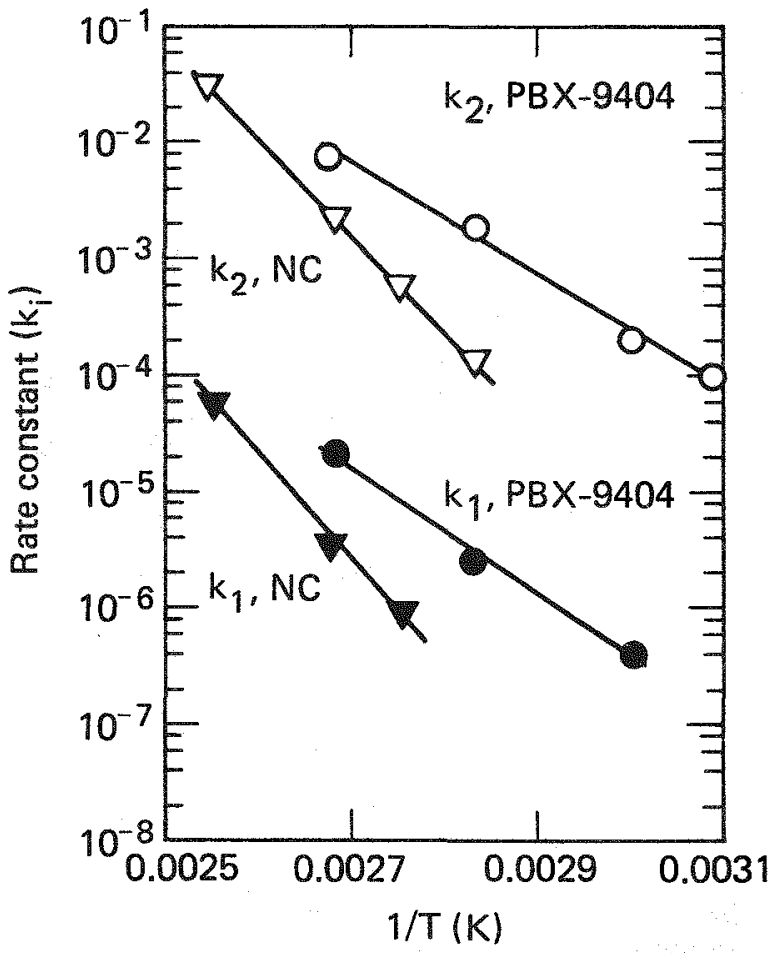

FIG. 3. Arrhenius plot of rate constant vs $(1 / T)$ for degradation of $\mathrm{NC}$ alone and NC in PBX-9404. The open symbols are for second-order nitrate ester decomposition, and the full symbols are for first-order molecular weight degradation. The circles are for NC in PBX-9404, and the triangles for $\mathrm{NC}$ alone. 
PBX-9404 is complicated and subject to large errors due to interference from HMX, RDX, nitrated DPA products, etc. The correlation is given by Eq. (3):

$$
\begin{aligned}
& \frac{1}{\bar{M}_{n}(0)}\left[\frac{\bar{M}_{n}(0)}{\bar{M}_{n}(t)}-1\right] \\
& =\frac{A_{2}}{A_{1}}\left[\frac{1}{C(0)}\right]\left[\frac{C(0)}{C(t)}-1\right] .
\end{aligned}
$$

The terms $A_{1}$ and $A_{2}$ are the pre-exponential factors in the first- and second-order rate expressions, respectively. When the left hand quantity of Eq. (3) is plotted versus the right hand variable, we expect a straight line with slope $A_{2} / A_{1}$. This plot is shown in Fig. 4 and the associated terms of Eq. (3) are given in Table 3 . A least-squares straight-line was fitted to the data. The slope (indicating the value of $A_{2} / A_{1}$ ) was $1.8 \times 10^{-3}$, with $r^{2}=0.87{ }^{*}$

A linear fit does not weight many of the NC data points because they fall close to the origin, so we also tried a least-squares fit to the power expression

$$
\begin{aligned}
\frac{1}{\bar{M}_{n}(0)}\left[\frac{\bar{M}_{n}(0)}{\bar{M}_{n}(t)}-1\right] & =B \quad\left\{\left[\frac{1}{C(0)}\right]\left[\frac{C(0)}{C(t)}-1\right]\right\}^{n} .
\end{aligned}
$$

The fit gave $n=0.96$ and $B=1.8 \times 10^{-3}$, with $r^{2}$ $=0.91$. This is essentially equivalent to the fit with Eq. (3), which we will assume to be correct.

We observed another difference in behavior between NC in PBX-9404 and pure NC, namely, that the molecular weight dispersities were very different after degradation. We have plotted the molecular weight dispersity (MWD) as a function of $\bar{M}_{n}(t)$ in Fig. 5. (The molecular weight dispersity is defined as MWD $=\left(\overline{\mathrm{M}}_{\mathrm{w}}\right) /\left(\overline{\mathrm{M}}_{\mathrm{n}}\right)$, where $\overline{\mathbf{M}}_{\mathrm{w}}$ is the weight-averaged molecular weight.) For

*The intercept was $1.1 \times 10^{-5}$.

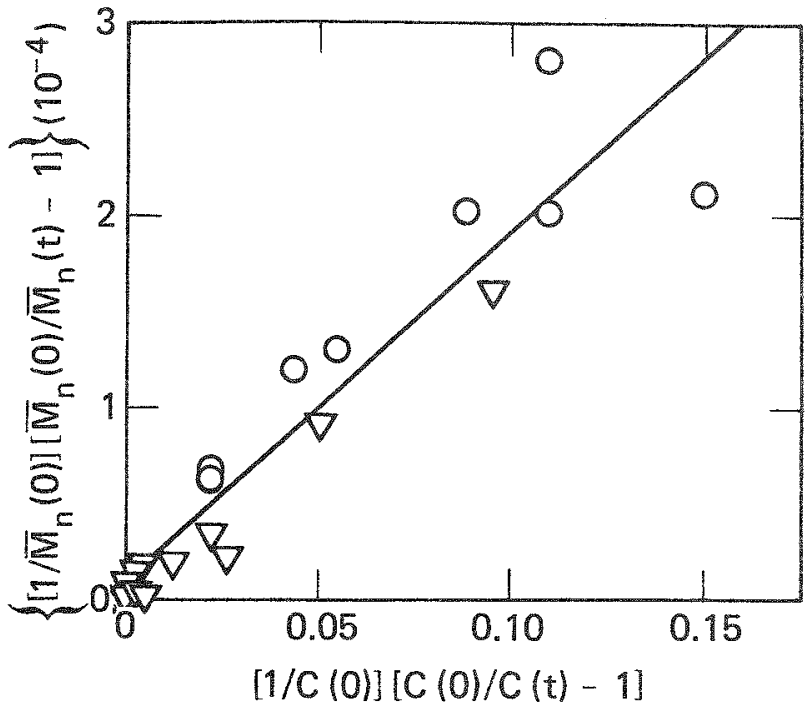

FIG.4. Nitrate ester decomposition and molecular weight degradation. Circles are for NC in PBX-9404; the triangles are for $\mathrm{NC}$ alone.

NC, MWD remains essentially constant throughout the process, while for PBX-9404, MWD decreases linearly with $\bar{M}_{n}$ and approaches a monodisperse state for total degradation $\left(\bar{M}_{n}(\hat{\imath}) \rightarrow 0\right)$. The significance of this finding is not obvious, but it certainly reflects the effects of the other ingredients of PBX-9404 on the NC decomposition process.

Observations in our previous study have led us to suggest that in the course of $\mathrm{NC}$ decomposition in PBX-9404 the tri-esterified NC units decompose first. ${ }^{2}$ However, Volltrauer and Fontijn ${ }^{4}$ interpreted their results as indicating that diesters were the first to decompose. We have reexamined our data and want to present another argument that the triesters are the first to disappear.

Several possible distributions of fully and partially esterified cellulose units yielding a cellulose nitrate with $\mathrm{X}=2.31$ were calculated using a Monte Carlo method. ${ }^{2}$ Of these, the one that best conforms to our results was one in which mono-, di-, and tri-esters were allowed, but no unesterified units were allowed. The results of that calculation are summarized in Table 4. Given the analyses in Ref. 2 for nitrate ester content, NC content and fractional decomposition of $\left(-\mathrm{ONO}_{2}\right)$ and $\mathrm{NC}$, we can calculate the mean ester number of the residual and the decomposed NC. These values are plotted in Fig. 6. The full symbols represent 
TABLE 3. Calculated values for Eqs. (1) and (2). (Dashes indicate data not obtained.)

\begin{tabular}{|c|c|c|c|c|c|}
\hline \multirow[b]{2}{*}{$\mathrm{T}\left({ }^{\circ} \mathrm{C}\right)$} & \multirow[b]{2}{*}{1 (days) } & $\frac{1}{\overline{\mathbf{M}}_{\mathbf{n}}(0)}$ & {$\left[\frac{\bar{M}_{n}(0)}{\bar{M}_{n}(t)}-1\right]^{*}$} & $\frac{1}{C(0)}$ & {$\left[\frac{\mathrm{C}(0)}{\mathrm{C}(\mathrm{t})}-1\right]$} \\
\hline & & PBX-9404 & $\mathrm{NC}$ & $\overline{\mathrm{PBX}-9404}$ & $\mathrm{NC}$ \\
\hline \multirow[t]{2}{*}{50} & 243 & $6.3 \times 10^{-5}$ & - & 0.022 & - \\
\hline & 488 & $1.0 \times 10^{-4}$ & - & - & - \\
\hline \multirow[t]{3}{*}{60} & 61 & $6.9 \times 10^{-5}$ & - & 0.022 & - \\
\hline & 243 & $1.2 \times 10^{-6}$ & - & 0.043 & - \\
\hline & 488 & $2.0 \times 10^{-6}$ & - & 0.11 & - \\
\hline \multirow[t]{7}{*}{80} & 20 & - & $7.7 \times 10^{-6}$ & - & $\leqslant 0.001^{\mathrm{a}}$ \\
\hline & 28 & $1.3 \times 10^{-6}$ & - & 0.055 & - \\
\hline & 30 & - & $1.5 \times 10^{-5}$ & - & 0.0038 \\
\hline & 59 & $2.0 \times 10^{-4}$ & - & 0.089 & - \\
\hline & 84.3 & $2.1 \times 10^{-4}$ & - & 0.15 & - \\
\hline & $89^{b}$ & $2.2 \times 10^{-}$ & - & 0.11 & - \\
\hline & $91^{b}$ & $4.5 \times 10^{-6}$ & - & 0.17 & - \\
\hline \multirow[t]{3}{*}{90} & 5 & - & $3.1 \times 10^{-7}$ & - & $\leqslant 0.001^{\mathrm{a}}$ \\
\hline & 10 & - & $4.4 \times 10^{-6}$ & - & 0.0038 \\
\hline & 20 & - & $1.7 \times 10^{-5}$ & - & 0.012 \\
\hline \multirow[t]{4}{*}{100} & 2 & - & $3.7 \times 10^{-6}$ & - & 0.0019 \\
\hline & 5 & - & $1.9 \times 10^{-5}$ & - & 0.0057 \\
\hline & 10 & - & $3.3 \times 10^{-5}$ & - & 0.022 \\
\hline & 14.2 & $2.8 \times 10^{-}$ & - & 0.11 & - \\
\hline \multirow[t]{3}{*}{120} & 1 & - & $2.2 \times 10^{-5}$ & - & 0.026 \\
\hline & 2 & - & $9.0 \times 10^{-5}$ & - & 0.050 \\
\hline & 3 & - & $1.6 \times 10^{-4}$ & - & 0.096 \\
\hline
\end{tabular}

*Molecular weight degradation.

$\uparrow$ Nitrate ester loss.

astimated, because our method was not sensitive enough to detect the change in the ester content.

These samples had begun accelerated decomposition 1,2 and were not included in the data analyses.

decomposed NC and the open symbols are for the residual NC. The solid curves are calculated on the following assumptions: the mean ester number (X) starts at 2.31; the NC subunit population is that shown in Table 4; at first triesters disappear exclusively; when the triesters are gone, the remaining $\mathrm{NC}$, consisting of mono- and di-esters only, decomposes congruently. It is evident that this simple picture is in good agreement with observations.
TABLE 4. Result of the Monte Carlo calculation for population of esterified subunits in $\mathrm{NC}$ with $X=2.31$.

\begin{tabular}{lc}
\hline NC subunit & Mole fraction \\
\hline Non-esterified & 0 \\
Monoesters & 0.186 \\
Diesters & 0.318 \\
Triesters & 0.496 \\
\hline
\end{tabular}




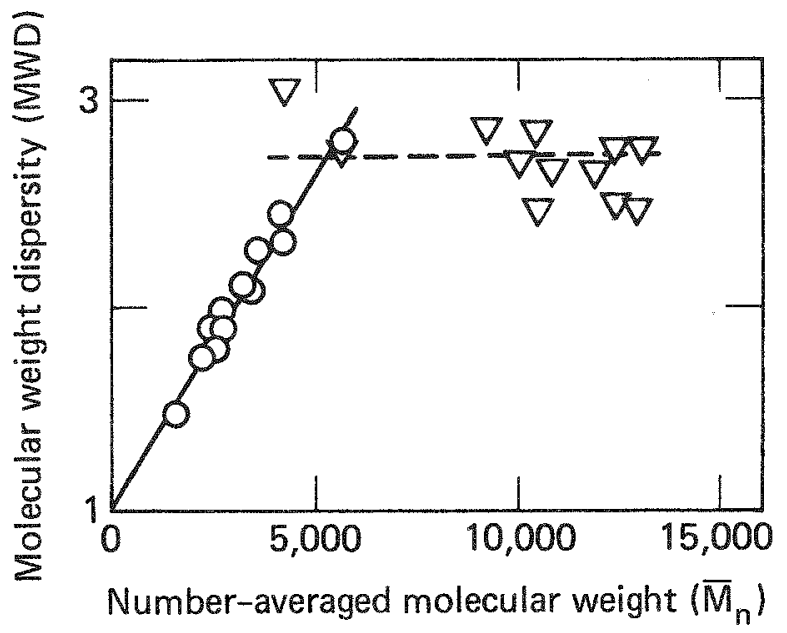

FIG. 5. Molecular weight dispersity and numberaveraged molecular weight. Circles are for $\mathrm{NC}$ in PBX-9404; the triangles are for $\mathrm{NC}$ alone.

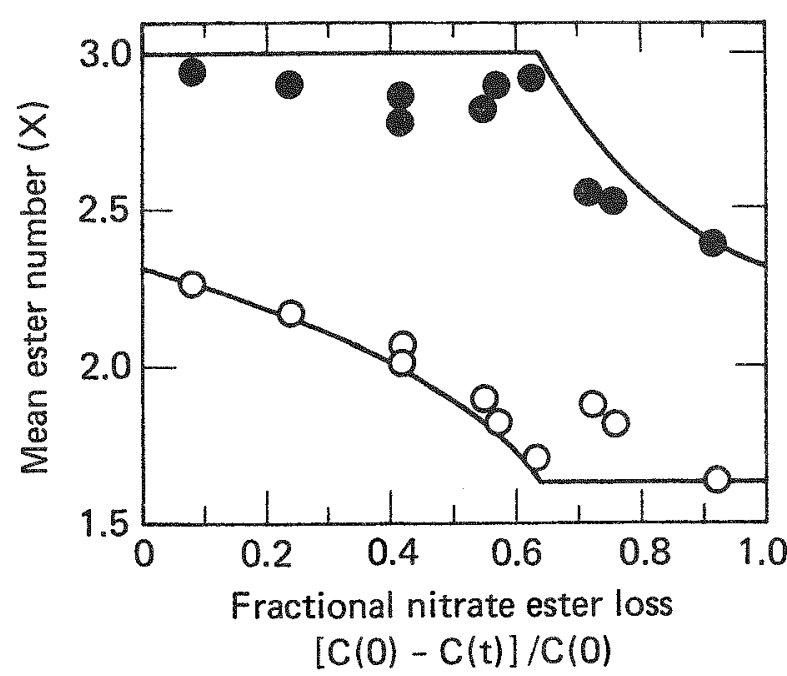

FIG. 6. Residual NC in PBX-9404 (open circles) and decomposed NC (full circles) as a function of fractional loss of nitrate ester. The lines represent a model that assumes that triesterified NC subunits decompose first.

\section{CONCLUSIONS}

The kinetics of decomposition of $\mathrm{NC}$, both "pure" and in PBX-9404, are shown to be consistent with (a) the simple first-order model of random chain-scission with respect to molecular weight degradation, and (b) a second-order nitrate ester decomposition. We also found that the activation energies characterizing the processes between 50 and $120^{\circ} \mathrm{C}$ are in agreement with available values in the literature. A change in the decomposition process is seen between 80 and $100^{\circ} \mathrm{C}$. A correlation has been calculated between molecular weight and nitrate ester content of NC that can be used predictively. It has been confirmed that, at a given temperature, decomposition of NC in PBX-9404 is faster than undiluted NC. The polydispersity of $\mathrm{NC}$ after decomposition remains constant for $\mathrm{NC}$ alone while it becomes more narrow for NC in PBX-9404. Finally, additional calculations indicate that for $\mathrm{NC}$ decomposition in PBX-9404 the triesterified subunits decompose first.

\section{ACKNOWLEDGEMENTS}

We thank J. E. Clarkson and Jane Cupps for the molecular weight determinations, R. H. Sanborn for the nitrate ester assays and D. M. Hoffman and D. L. Seaton for informative discussions. 


\section{REFERENCES}

1. H. R. Leider and D. L. Seaton, Gas Evolution and Weight Loss from Thermal Decomposition of PBX-9404 Below $100^{\circ} \mathrm{C}$, Lawrence Livermore National Laboratory, Livermore, CA, UCRL-52692 (1979).

2. H. R. Leider and D. L. Seaton, Nitrate Ester Decomposition and Degradation of Molecular Weight in Nitrocellulose from Thermal Decomposition of PBX-9404 below $100^{\circ} \mathrm{C}$, Lawrence Livermore National Laboratory, Livermore, CA, UCRL-52776 (1979).

3. W. H. Rogers and L. C. Smith, The Effect of Long-Term Storage at $60^{\circ} \mathrm{C}$ on Small Cylinders of PBX-9404, Los Alamos National Laboratory, Los Alamos, NM, LA-4989-MS (1972).

4. H. N. Volltrauer and A. Fontijn, Low Temperature Pyrolysis Studies by Chemiluminescence Techniques. Real-Time Nitrocellulose and PBX-9404 Decomposition, AeroChem Laboratories, Princeton, NJ, TP-390 (1980).

5. F. Walker, Thermal Decomposition of PBX-9404 as a Function of Time and Temperature, Lawrence Livermore National Laboratory, Livermore, CA, UCID-15667 (1970).

6. L. C. Myers, Thermochemical Decomposition of a Double-Based Propellant-AAH. Part II, Mason and Hanger-Silas Mason Co., Inc., Amarillo, TX, Pantex Plant MHSMP-77-59 (1977).

7. M. Frey, "Lifetime of Rocket Propellants, Gun Propellants and Explosive Charges," in Proc. Inst. für Chemie der Treib- und Explosivstoffe 1970 (Karlsruhe, W. Germany, 1970), p. 105.

8. F. Volk, "Lifetime of Rocket Propellants, Gun Propellants and Explosive Charges," in Proc. Inst. für Chemie der Treib- und Explosivstoffe 1970 (Karlsruhe, W. Germany, 1970), p. 125.

9. R. N. Rogers, "Lifetime of Rocket Propellants, Gun Propellants and Explosive Charges," in Proc. Inst. für Chemie der Treib- und Explosivstoffe 1970 (Karlsruhe, W. Germany, 1970), p. 41.

10. J. L. C. Van Geel, The Self-Ignition Hazards of Nitrate Ester Propellants, Ph.D. Thesis, Technische Hogeschool, Delft, The Netherlands (1969).

11. H. Mark and A. V. Tobolsky, Physical Chemistry of High Polymer Systems (Interscience Publishers, Inc., New York, 1960), pp. 459-465.

12. D. M. Hoffman and L. E. Caley, "Dynamic Mechanical and Molecular Weight Measurements on Five Polymer Bonded Explosives from Thermally Accelerated Aging Tests," in Papers presented at the Atlanta Meeting, 1981 (Division of Polymer Chemistry, Inc., American Chemical Society, New York, 1981), vol. 22, no. 1, p. 320.

13. B. M. Dobratz, Ed., Properties of Chemical Explosives and Explosive Simulants, Lawrence Livermore National Laboratory, Livermore, CA, UCRL-52997 (1981).

14. J. B. Apatoff and G. Norwitz, Frankford Arsenal, Philadelphia, PA, T73-12-1 (1973). 
Technical Information Department - Lawrence Livermore National Laboratory University of California · Livermore, California 94550

\section{First Class Mail}

